\title{
Hierarchic Analysis Method to Evaluate Rock Burst Risk
}

\author{
Ming Ji, ${ }^{1}$ Hong-jun Guo, ${ }^{1}$ Yi-dong Zhang, ${ }^{2}$ Tao Li, ${ }^{1}$ and Lin-sheng Gao ${ }^{2,3}$ \\ ${ }^{1}$ Key Laboratory of Deep Coal Resource Mining, School of Mines, Ministry of Education of China, \\ China University of Mining and Technology, Xuzhou 221116, China \\ ${ }^{2}$ State Key Laboratory of Coal Resources and Safe Mining, China University of Mining \& Technology, Xuzhou 221116, China \\ ${ }^{3}$ North China Institute of Science \& Technology, Yanjiao, Beijing East 101601, China
}

Correspondence should be addressed to Lin-sheng Gao; gaolinsheng@ncist.edu.cn

Received 17 April 2015; Accepted 16 July 2015

Academic Editor: Peter Dabnichki

Copyright (c) 2015 Ming Ji et al. This is an open access article distributed under the Creative Commons Attribution License, which permits unrestricted use, distribution, and reproduction in any medium, provided the original work is properly cited.

\begin{abstract}
In order to reasonably evaluate the risk of rock bursts in mines, the factors impacting rock bursts and the existing grading criterion on the risk of rock bursts were studied. By building a model of hierarchic analysis method, the natural factors, technology factors, and management factors that influence rock bursts were analyzed and researched, which determined the degree of each factor's influence (i.e., weight) and comprehensive index. Then the grade of rock burst risk was assessed. The results showed that the assessment level generated by the model accurately reflected the actual risk degree of rock bursts in mines. The model improved the maneuverability and practicability of existing evaluation criteria and also enhanced the accuracy and science of rock burst risk assessment.
\end{abstract}

\section{Introduction}

Rock bursts are dynamic disasters in coal mines involving coal or rock. When the strength limit of the coal rock mass mechanical system is reached, the energy accumulated in the mine roadway and the coal rock around the stop is released suddenly, sharply, and violently. The power generated by these explosive accidents throws coal and rock into the roadways. Generally, the coal rock mass vibrates, and the explosion destroys the supports, facility, and roadways and can also result in human casualties. Rock bursts may also lead to other mine disasters such as gas and coal dust explosions, fires, floods, and destruction of the ventilation systems and even cause the ground above to shake and damage to buildings [1-3].

Rock bursts are a typical dynamic disaster in the coal mining process and are a direct threat to coal production and the safety of persons and property. Rock bursts have become a topic of interest in rock mechanics research. They are influenced by many factors, happen suddenly, and are highly destructive. Therefore, it is essential to provide a theoretical basis for controlling rock bursts; this can be done by studying regular patterns and precursor information to evaluate the risk degree of the occurrence of rock bursts [3].
Mu et al. $[4,5]$ studied the mechanism of roof strata impacting coal bursts by physical simulation experiments, UDEC discrete element numerical simulations, theoretical analysis, and engineering practices. Then, they proposed the principle of coal rock burst failure and roof strata inducing burst and the damage criterion for rock bursts. Their work provided guidelines for the prevention and control of rock bursts.

Li et al. [6] simulated the impact of faults on mine pressure distribution in coal mining processes. They studied the change law of the peak supporting pressure in the working face under different conditions such as different fault dips, strength, fall, and main roof thickness. The results showed that peak supporting pressure decreased when the fault dip decreased as the working face advanced up the fault wall to the fault. Conversely, the peak increased rapidly first and then stayed steady when the main roof's strength increased. The rock burst hazard is less likely in the former condition than in the latter.

He et al. [7] used a microseismic monitoring system to study the temporal and spatial variations of the mining processes in the working face of the Huating coal mine, which is in an earthquake zone: synclinal axis is prone to strong mining earthquake and high impact force; the 
TABLE 1: Magnitude strength and throw coal method of rock burst evaluation.

\begin{tabular}{lcc}
\hline $\begin{array}{l}\text { Magnitude } \\
\text { strength }\end{array}$ & $\begin{array}{c}\text { Weight of } \\
\text { thrown coal/t }\end{array}$ & Risk level \\
\hline$<1$ & 5 & Micro shock (level I) \\
$<1$ & $5-10$ & Weak shock (level II) \\
$1-2$ & $10-50$ & Medium impact (level III) \\
$>2$ & $>50$ & Shock (level IV) \\
\hline
\end{tabular}

TABLE 2: Research mine rock burst risk rating.

\begin{tabular}{lcccccccccc}
\hline Mine number & 1 & 2 & 3 & 4 & 5 & 6 & 7 & 8 & 9 & 10 \\
\hline Risk rating & II & III & IV & IV & I & III & II & II & IV & IV \\
\hline
\end{tabular}

cycle of strong mining earthquake is short and of high frequency, and before strong mining earthquake occurred, the vibration energy appeared "calm" or downward trend, which along with the number rising energy shock can be used as precursory information for predicting the synclinal strong mining earthquake.

Dou et al. [8, 9] studied monitoring principles and classification criteria to forecast shock hazards and formed the temporal classification prediction system for rock bursts. Practice has proved that this technology greatly improved the accuracy of the prediction of rock bursts.

Ge et al. [10], Yi et al. [11], and Li et al. [12] used a fuzzy evaluation model and analytic hierarchy process to study the degree of influence of each factor in rock bursts and to determine the danger level of rock bursts in order to provide a feasible method for mine evaluation and the prediction of dynamic disasters of rock bursts.

Song et al. [13] studied the relationship between entropy equation and dissipative structures and proposed a system of rock burst activity and analyzed it by its entropy. The results showed that rock bursts generally occur in dissipative structures. Then, they would form a new and ordered structure and achieved good results through practical application in Yanbei mine.

Adoko et al. [14] used a fuzzy inference system, adaptive neural fuzzy inference system, and measured data to study the relationship between a rock burst and its influencing factors and to predict the intensity of rock bursts under mitigating conditions. Their method was in good agreement with actual situations, suggesting that it is effective for predicting the impact of mine dangers.

Dong et al. $[15,16]$ used the engineering of 36 mines from home and abroad in rock burst conditions and data for training samples and established a random forest analysis model of rock burst grade determination. At the same time, they used the samples that did not participate in the training sample for model testing and evaluation, and the results highly coincided with actual records. Compared to the SVM and neural network method, the false positive rate of the random forest analysis model was reduced by $10 \%$ and $20 \%$, respectively, and it provided an effective method to determine the grade of rock bursts.
TABLE 3: Judgment matrix.

\begin{tabular}{lcccc}
\hline Judgment matrix $P$ & $D_{1}$ & $D_{2}$ & $\cdots$ & $D_{n}$ \\
\hline$D_{1}$ & $D_{11}$ & $D_{12}$ & $\cdots$ & $D_{1 n}$ \\
$D_{2}$ & $D_{21}$ & $D_{22}$ & $\cdots$ & $D_{2 n}$ \\
$\vdots$ & $\vdots$ & $\vdots$ & $\vdots$ & $\vdots$ \\
$D_{n}$ & $D_{n 1}$ & $D_{n 2}$ & $\cdots$ & $D_{n n}$ \\
\hline
\end{tabular}

TABLE 4: The relative importance judgment of each element.

\begin{tabular}{lc}
\hline Scale & Meaning \\
\hline 1 & The importance of $D_{i}$ and $D_{j}$ is equal \\
3 & $D_{i}$ and $D_{j}$ are slightly important \\
5 & $D_{i}$ and $D_{j}$ are obviously important \\
7 & $D_{i}$ and $D_{j}$ are strongly important \\
9 & $D_{i}$ and $D_{j}$ are vitally important \\
$2,4,6,8$ & The median of two adjacent judgments \\
Reciprocal & $D_{i j}=\frac{1}{D_{j i}}$ \\
\hline
\end{tabular}

TABLE 5: Average random consistency index RI.

\begin{tabular}{cccccccccc}
\hline$n$ & 1 & 2 & 3 & 4 & 5 & 6 & 7 & 8 & 9 \\
\hline $\mathrm{RI}$ & 0 & 0 & 0.58 & 0.9 & 1.12 & 1.24 & 1.32 & 1.41 & 1.45 \\
\hline
\end{tabular}

\section{Rock Burst Evaluation Basis and Risk Level of the Research Object}

Existing research on the basis of magnitude strength and throw coal categorized rock bursts into four levels: micro shock (level I), weak shock (level II), medium impact (level III), and shock (level IV). The risk classification bases are shown in Table 1.

The rock burst risk rating of ten mines which followed the standard in Table 1 was shown in Table 2.

The weight of thrown coal is not easy to determine and divide and fewer influence factors were considered in the classification method above, so the operability of the method is poor, and it should not be full used in comprehensive evaluation of rock burst influence factors analysis. And the coal magnitude strength and the weight of thrown coal also have little effect in control or reduce the influence of coal rock burst.

\section{Rock Burst Influence Factors Analysis}

The reasons for the occurrence of rock bursts are complex and various and can generally be divided into three types: natural factors, technical factors, and organizational management. Natural factors include mining depth, mechanical properties of coal and rock, geological structure, coal thickness, and burst tendency of coal rock. Technical factors include roof control, degree of production concentration, pressure relief, and rings of coal burst. Organizational management factors 
TABle 6: Judgment matrix $A-B$ and parameters.

\begin{tabular}{|c|c|c|c|c|c|c|}
\hline & $\begin{array}{l}\text { Natural } \\
\text { factors }\end{array}$ & $\begin{array}{l}\text { Geological } \\
\text { factors }\end{array}$ & $\begin{array}{c}\text { Organization } \\
\text { management factors }\end{array}$ & Weight & Maximum eigenvalue & Consistency ratio \\
\hline Natural factors & 1 & 3 & 4 & 0.6337 & \multirow{3}{*}{3.0092} & \multirow{3}{*}{$0.0089<0.10$} \\
\hline Geological factors & $1 / 3$ & 1 & 1 & 0.1919 & & \\
\hline Organization management factors & $1 / 4$ & 1 & 1 & 0.1744 & & \\
\hline
\end{tabular}

TABLE 7: Judgment matrix $B_{1}-C$ and parameters.

\begin{tabular}{lccccccc}
\hline Judgment matrix & $\begin{array}{c}\text { Mining } \\
\text { depth }\end{array}$ & $\begin{array}{c}\text { Mechanical } \\
\text { properties } \\
\text { of coal and } \\
\text { rock }\end{array}$ & $\begin{array}{c}\text { Geological } \\
\text { structure }\end{array}$ & $\begin{array}{c}\text { Coal } \\
\text { thickness }\end{array}$ & $\begin{array}{c}\text { Burst } \\
\text { tendency } \\
\text { of coal } \\
\text { rock }\end{array}$ & Weight Maximum eigenvalue Consistency ratio \\
\hline $\begin{array}{l}\text { Mining depth } \\
\text { Mechanical properties of }\end{array}$ & 1 & $1 / 2$ & 4 & 3 & 3 & 0.2636 \\
coal and rock & 2 & 1 & 7 & 5 & 5 & 0.4758 & 5.0721 \\
Geological structure & $1 / 4$ & $1 / 7$ & 1 & $1 / 2$ & $1 / 3$ & 0.0538 & $0.0161<0.1$ \\
Coal thickness & $1 / 3$ & $1 / 5$ & 2 & 1 & 1 & 0.0981 & 0.1087 \\
Burst tendency of coal rock & $1 / 3$ & $1 / 5$ & 3 & 1 & 1 & & \\
\hline
\end{tabular}

TABLE 8: Judgment matrix $B_{2}-C$ and parameters.

\begin{tabular}{|c|c|c|c|c|c|c|c|}
\hline Judgment matrix & $\begin{array}{c}\text { Roof } \\
\text { control }\end{array}$ & $\begin{array}{l}\text { Degree of production } \\
\text { concentration }\end{array}$ & $\begin{array}{c}\text { Pressure } \\
\text { relief }\end{array}$ & $\begin{array}{l}\text { Rings of } \\
\text { coal burst }\end{array}$ & Weight & Maximum eigenvalue & Consistency ratio \\
\hline Roof control & 1 & $1 / 3$ & $1 / 5$ & 2 & 0.1098 & \multirow{4}{*}{4.0201} & \multirow{4}{*}{$0.0075<0.10$} \\
\hline $\begin{array}{l}\text { Degree of production } \\
\text { concentration }\end{array}$ & 3 & 1 & $1 / 2$ & 5 & 0.3005 & & \\
\hline Pressure relief & 5 & 2 & 1 & 7 & 0.5267 & & \\
\hline Rings of coal burst & $1 / 2$ & $1 / 5$ & $1 / 7$ & 1 & 0.0630 & & \\
\hline
\end{tabular}

TABLE 9: Judgment matrix $B_{3}-C$ and parameters.

\begin{tabular}{lcccccc}
\hline Judgment matrix & Investment & Prevention measures & Training & Weight & Maximum eigenvalue & Consistency ratio \\
\hline Investment & 1 & $1 / 3$ & 2 & 0.2493 & 3.0536 & $0.0515<0.10$ \\
Prevention measures & 3 & 1 & 3 & 0.5936 & 0.1571 & \\
Training & $1 / 2$ & $1 / 3$ & 1 & \\
\hline
\end{tabular}

include investments, such as improper measures taken and training, as shown in Figure 1.

\section{Establishing the Analytic Hierarchy Process (AHP) Model}

In order to improve the operability and practicability of evaluations on the basis of risk grades, analytic hierarchy process (AHP) model was established to grade evaluations and provide guidance.

4.1. The Principle of Analytic Hierarchy Process (AHP). Analytic hierarchy processes regard complicated multiobjective decision-making problems as a system in which the target is decomposed into multiple goals or standards and multiple indices of several levels through the qualitative index fuzzy quantification method to calculate single hierarchy sorting and total ordering.
Hierarchic analysis method can be simplified into following steps.

(1) Construction of judgment matrix: the judgment matrix is used to represent the importance of every element relative to one of the upper elements, the form of which is shown in Table $3 . D_{i j}$ is the element judgment matrix $P$ and is given based on the 1-9 scale put forward by Saaty [17], as shown in Table 4.

(2) The weight and maximum eigenvalue $\lambda_{\max }$ of judgment matrix.

(a) Calculation of $O_{i}$ product of elements in every row of judgment matrix is as follows:

$$
O_{i}=\prod_{j=1}^{n} d_{i j}, \quad i=1,2,3, \ldots, n .
$$




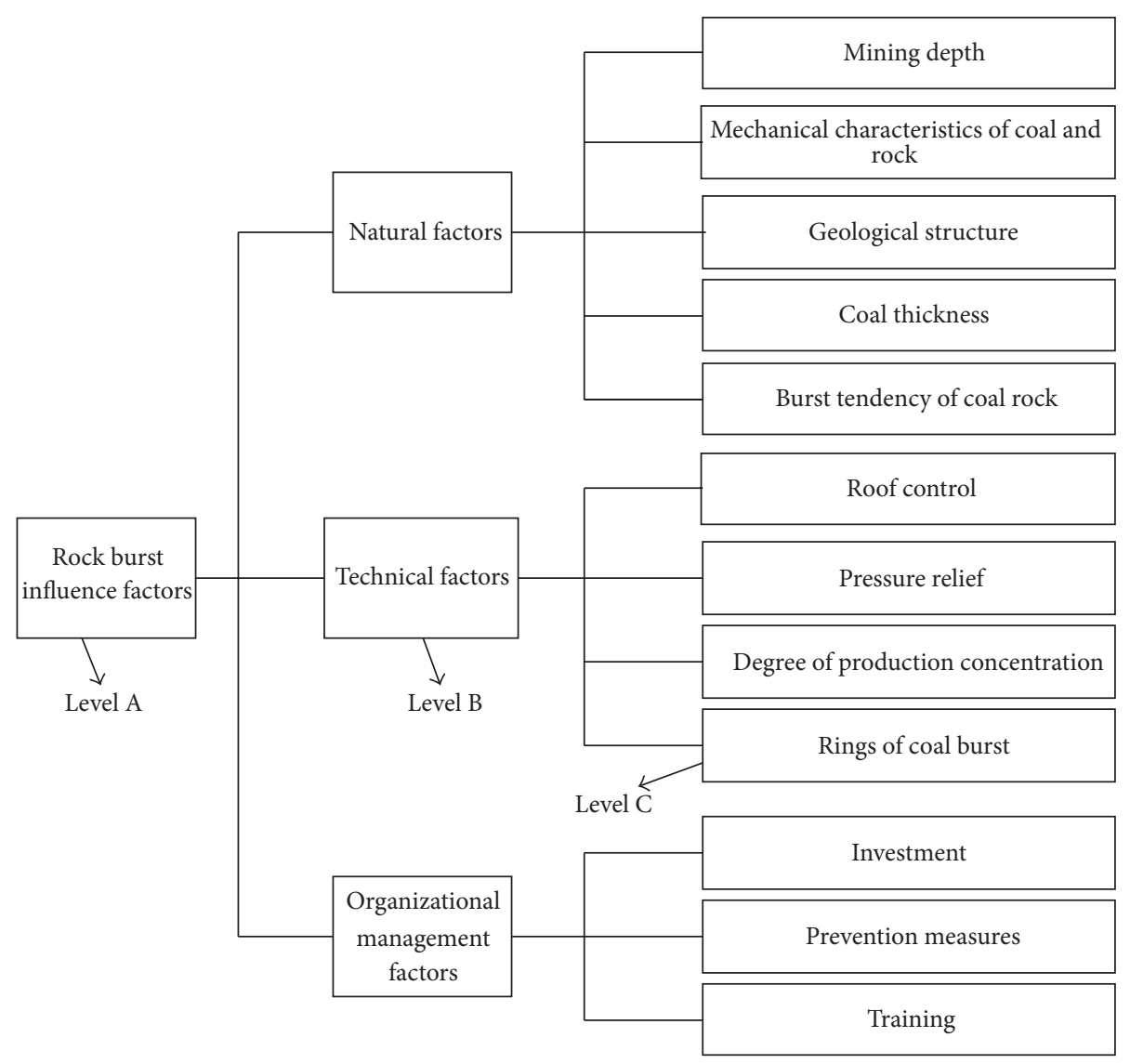

FIGURE 1: Rock burst influence factors.

TABLE 10: Every factor weight summary table.

\begin{tabular}{|c|c|c|c|c|}
\hline & First grade index & Weight & Second index & Weight \\
\hline \multirow{12}{*}{$\begin{array}{l}\text { Analysis on factors } \\
\text { affecting impulsion } \\
\text { pressure }\end{array}$} & \multirow{4}{*}{ Natural factors } & \multirow{4}{*}{0.10473} & Mining depth & 0.16705 \\
\hline & & & Mechanical properties of coal and rock & 0.30154 \\
\hline & & & Geological structure & 0.034103 \\
\hline & & & Coal thickness & 0.062147 \\
\hline & \multirow{4}{*}{ Technical factors } & \multirow{4}{*}{0.63699} & Burst tendency of coal rock & 0.06887 \\
\hline & & & Roof control & 0.021066 \\
\hline & & & Degree of production concentration & 0.057676 \\
\hline & & & Pressure relief & 0.10109 \\
\hline & \multirow{4}{*}{ Organization management factors } & \multirow{4}{*}{0.25828} & Rings of coal burst & 0.012089 \\
\hline & & & Investment & 0.043473 \\
\hline & & & Prevention measures & 0.10351 \\
\hline & & & Training & 0.027386 \\
\hline
\end{tabular}

TABLE 11: Mining depth and quantitative scores.

\begin{tabular}{lccccc}
\hline Mining depth $/ \mathrm{m}$ & $<350$ & $350-500$ & $500-800$ & $800-1000$ & $>1000$ \\
\hline Scores & 2 & 4 & 6 & 8 & 10 \\
\hline
\end{tabular}

TABle 12: Physical and mechanical characteristics of coal and surrounding rock and quantitative scores.

\begin{tabular}{lccccc}
\hline Impact energy index & $<1$ & $1-1.5$ & $1.5-3$ & $3-5$ & $>5$ \\
\hline Elastic energy index & $<1$ & $1-2$ & $2-3.5$ & $3.5-5$ & $>5$ \\
\hline Scores & 2 & 4 & 6 & 8 & 10 \\
\hline
\end{tabular}


TABLE 13: Geological structure and quantitative scores.

\begin{tabular}{lccccc}
\hline $\begin{array}{l}\text { Geological } \\
\text { structure types }\end{array}$ & $\begin{array}{c}\text { Local } \\
\text { anomaly }\end{array}$ & $\begin{array}{c}\text { Local structure } \\
\text { anomaly }\end{array}$ & $\begin{array}{c}\text { Coal seam thickness variation, } \\
\text { thinning and thinning out, and } \\
\text { cavity }\end{array}$ & $\begin{array}{c}\text { Roof and } \\
\text { floor fold }\end{array}$ & $\begin{array}{c}\text { Downfold, } \\
\text { upfold, and } \\
\text { fault }\end{array}$ \\
\hline Scores & 2 & 4 & 6 & 8 & 10 \\
\hline
\end{tabular}

(b) Calculation of $v$ th root of $O_{i}$ is as follows:

$$
\overline{E_{i}}=\sqrt[n]{\mathrm{O}_{i}}
$$

(c) Standardization of the matrix $\bar{E}=\left[\bar{E}_{1}, \bar{E}_{2}, \ldots\right.$, $\left.\bar{E}_{n}\right]^{T}$ is as follows:

$$
E_{i}=\frac{\overline{E_{i}}}{\sum_{i=1}^{n} \overline{E_{i}}} .
$$

$E=\left[E_{1}, E_{2}, \ldots, E_{n}\right]^{T}$ is the eigenvector figured out.

(d) Calculation of $\lambda_{\max }$ maximum eigenvalue of eigenvector is as follows:

$$
\lambda_{\max }=\frac{1}{v} \sum_{i=1}^{V} \frac{(\mathrm{PE})_{i}}{E_{i}} .
$$

(3) Consistency check of judgment matrix includes the following.

(a) Calculation of consistency index CI is as follows:

$$
\mathrm{CI}=\frac{\lambda_{\max }-v}{v-1} \text {. }
$$

(b) Verification of corresponding average random consistency index RI is as shown in Table 5.

(c) Calculation of consistency ratio CR is as follows:

$$
\mathrm{CR}=\frac{\mathrm{CI}}{\mathrm{RI}}
$$

When $\mathrm{CR}<0.10$, the consistency of the judgment matrix is considered reasonable, or proper correction should be made to the judgment matrix.

\subsection{Construction of Risk Evaluation Indices of Impulsion Pressure}

4.2.1. Construction of Index Judgment Matrix. According to the hierarchical structure diagrams of factors affecting impulsion pressure (shown in Figure 1), a preferential judgment matrix can be established as follows:

(1) Judgment matrix $A-B$ is shown in Table 6.

(2) Judgment matrix $B_{1}-C$ is shown in Table 7.

(3) Judgment matrix $B_{2}-C$ is shown in Table 8.

(4) Judgment matrix $B_{3}-C$ is shown in Table 9.

Based on judgment matrix constructed, the weight of every factor can be figured out by using Matlab [18]. The results are shown in Table 10.
TABLE 14: Coal seam thickness and quantitative scores.

\begin{tabular}{lccccc}
\hline Coal seam thickness $/ \mathrm{m}$ & $<2.0$ & $2.0-4.0$ & $4.0-6.0$ & $6.0-8.0$ & $>8.0$ \\
\hline Scores & 2 & 4 & 6 & 8 & 10
\end{tabular}

TABLE 15: Coal rock burst tendency and quantitative scores.

\begin{tabular}{lccccc}
\hline Elastic energy index & $<1.5$ & $1.5-3.0$ & $3.0-5.0$ & $5.0-7.0$ & $>7.0$ \\
\hline $\begin{array}{l}\text { Dynamic failure } \\
\text { time/ms }\end{array}$ & $<2.0$ & $2.0-3.0$ & $3.0-4.0$ & $4.0-5.0$ & $>5.0$ \\
\hline Scores & 2 & 4 & 6 & 8 & 10 \\
\hline
\end{tabular}

TABLE 16: Roof control and quantitative scores.

\begin{tabular}{lccccc}
\hline $\begin{array}{l}\text { Distance from hard } \\
\text { and thick roof to coal } \\
\text { seam/m }\end{array}$ & $<100$ & $100-80$ & $80-60$ & $60-40$ & $<40$ \\
\hline Scores & 2 & 4 & 6 & 8 & 10 \\
\hline
\end{tabular}

TABLE 17: Pressure relief circumstances and quantitative scores.

\begin{tabular}{lccccc}
\hline $\begin{array}{l}\text { Probability of stress } \\
\text { reduction/\% }\end{array}$ & $<25$ & $25-40$ & $40-55$ & $55-80$ & $>80$ \\
\hline Scores & 2 & 4 & 6 & 8 & 10 \\
\hline
\end{tabular}

4.2.2. Quantization and Standardization of the Risk Index of Rock Bursts. According to information on rock bursts in mines in China, the mining depth, gas content, and coal seam thickness, and so forth can be found. However, in order to meet the requirements of the model, it is necessary to quantify the qualitative description in the sample. The quantitative methods are as follows.

(1) Mining depth: Statistical analysis shows that the deeper the mining depth, the higher the possibility of a rock burst occurring. The quantitative values are shown in Table 11.

(2) Mechanical characteristics of coal and rock: Generally, for coal and rock, the more the energy retention is internally and the less the energy is released, the more the possibility of rock bursts occurs. The impact energy index and elastic energy index to characterize the mechanical properties of coal and rock are shown in Table 12.

(3) Geological structure: The power in the movement of strata generates a variety of geological structures, such as folds and faults, which have a greater effect on rock bursts. 
TABLE 18: The other factors and quantitative scores.

\begin{tabular}{lccccc}
\hline Degree of production centralization & None & Low & Medium & Relatively high & High \\
\hline Rings of coal burst & None & Few & Several times & Frequently & Uninterrupted \\
\hline Investment & High & Relatively high & In general & Less & None \\
\hline Prevention measures & Good effect & Fully & In general & Less & None \\
\hline Training & More & Relatively more & In general & Less & None \\
\hline Scores & 2 & 4 & 6 & 8 & 10 \\
\hline
\end{tabular}

TABLE 19: The quantitative values of the factors impacting rock bursts.

\begin{tabular}{|c|c|c|c|c|c|c|c|c|c|c|c|c|}
\hline $\begin{array}{l}\text { Mine } \\
\text { ID }\end{array}$ & $\begin{array}{l}\text { Mining } \\
\text { depth }\end{array}$ & $\begin{array}{l}\text { Mechanical } \\
\text { characteristics } \\
\text { of coal and } \\
\text { rock }\end{array}$ & $\begin{array}{l}\text { Geological } \\
\text { structure }\end{array}$ & $\begin{array}{c}\text { Coal } \\
\text { thickness }\end{array}$ & $\begin{array}{l}\text { Burst } \\
\text { tendency } \\
\text { of coal } \\
\text { rock }\end{array}$ & $\begin{array}{c}\text { Roof } \\
\text { control }\end{array}$ & $\begin{array}{l}\text { Pressure } \\
\text { relief }\end{array}$ & $\begin{array}{c}\text { Degree of } \\
\text { production } \\
\text { concentration }\end{array}$ & $\begin{array}{l}\text { Rings } \\
\text { of } \\
\text { coal } \\
\text { burst }\end{array}$ & Investment & $\begin{array}{c}\text { Prevention } \\
\text { measures }\end{array}$ & Training \\
\hline 1 & 6 & 2 & 4 & 2 & 4 & 10 & 4 & 6 & 6 & 4 & 8 & 4 \\
\hline 2 & 6 & 6 & 8 & 4 & 4 & 8 & 6 & 2 & 6 & 6 & 2 & 8 \\
\hline 3 & 8 & 6 & 10 & 4 & 10 & 6 & 4 & 10 & 8 & 4 & 8 & 8 \\
\hline 4 & 6 & 8 & 10 & 6 & 10 & 10 & 4 & 6 & 8 & 6 & 8 & 10 \\
\hline 5 & 6 & 2 & 2 & 2 & 4 & 2 & 10 & 6 & 2 & 4 & 2 & 4 \\
\hline 6 & 4 & 6 & 6 & 8 & 6 & 6 & 10 & 6 & 8 & 8 & 8 & 10 \\
\hline 7 & 4 & 4 & 2 & 2 & 8 & 4 & 8 & 4 & 4 & 4 & 6 & 4 \\
\hline
\end{tabular}

TABLE 20: Correlation table of risk rating of rock bursts.

\begin{tabular}{|c|c|c|c|c|c|c|c|}
\hline Mine ID & 1 & 2 & 3 & 4 & 5 & 6 & 7 \\
\hline Comprehensive index & 5.0038 & 6.0494 & 8.004 & 8.1954 & 3.6114 & 6.4552 & 4.2156 \\
\hline Actual grade & $\begin{array}{l}\text { Low } \\
\text { impact }\end{array}$ & $\begin{array}{c}\text { Medium } \\
\text { impact }\end{array}$ & $\begin{array}{l}\text { Strong } \\
\text { impact }\end{array}$ & $\begin{array}{l}\text { Strong } \\
\text { impact }\end{array}$ & $\begin{array}{c}\text { Micro-impact } \\
\text { Medium }\end{array}$ & $\begin{array}{c}\text { Medium } \\
\text { impact }\end{array}$ & $\begin{array}{l}\text { Low } \\
\text { impact }\end{array}$ \\
\hline
\end{tabular}

According to the relationship between the number of rock bursts and geological structures in coal mines, conclusions were drawn as detailed in Table 13.

(4) Coal seam thickness: According to statistics, coal seam thickness relates to the occurrence of rock bursts, corresponding to results in Table 14.

(5) Burst tendency of coal rock: Rock bursts can occur in any coal seam. The more brittle and hard the coal is, the less the impact energy is needed and the more it is likely to burst. So, impact energy index, elastic energy index, and dynamic destruction time are generally used to measure the possibility. The quantitative results are given in Table 15.

(6) Roof control: The occurrence of a rock burst is influenced by the strata mainly above the coal seam, which has great intensity and thickness, and the method of processing the roof such as packing and caving. The quantitative values are given in Table 16.

(7) Pressure relief circumstances: According to the actual effects of taking preventative measures, such as pressure relief blasting, drill hole pressure relief, and mining liberated seams, the likelihood of rock bursts occurring changes. The scores are given in Table 17.

(8) The other factors and quantitative scores are shown in Table 18.
TABLE 21: Evaluation of the risk of rock burst grade features by hierarchic analysis method.

\begin{tabular}{lc}
\hline The quantitative value of risk rating & Risk rating \\
\hline $2.0-4.0$ & Micro-impact (level I) \\
$4.0-6.0$ & Low impact (level II) \\
$6.0-8.0$ & Medium impact (level III) \\
$8.0-10.0$ & Strong impact (level IV) \\
\hline
\end{tabular}

4.3. Establishing the Comprehensive Index and Grade Features. Taking the first seven mines as the training samples of the hierarchic analysis method model, the quantitative values of the factors are shown in Table 19.

The comprehensive evaluation index of rock bursts can be obtained by multiplying the standardized data in Table 19 by the corresponding weights in Table 10. The specifics are shown in Table 20.

According to Table 20, by comparing the quantitative value of the comprehensive evaluation index of the risk of rock bursts and the actual rock burst strength, the risk of rock bursts can be divided into four grades. The quantitative value of the influencing factors of rock bursts in the range of 2.0 to 4.0 is representative of micro-impact (level I); the range of 4.0 to 6.0 is representative of low impact (level II); the range of 6.0 to 8.0 is representative of medium impact (level III); 


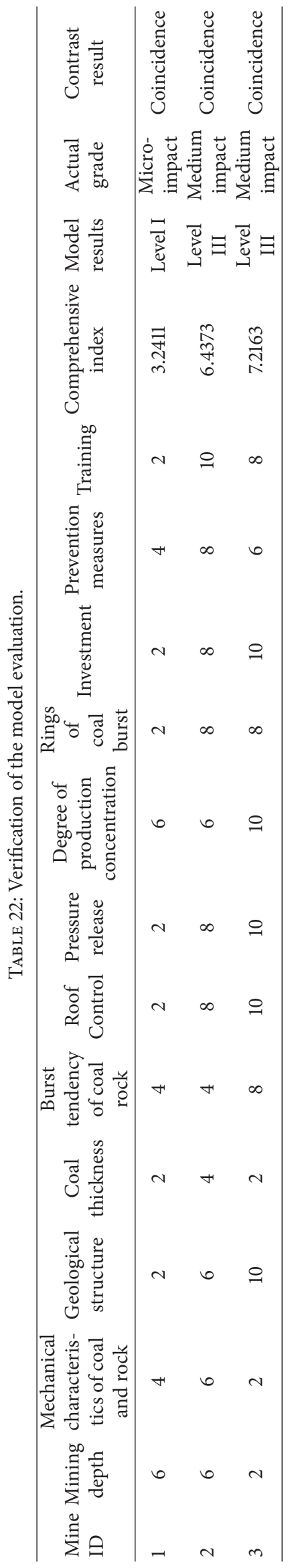


and the range of 8.0 to 10.0 is representative of strong impact (level IV), as shown in Table 21.

4.4. Verifying the Model Evaluation. To verify the model's applicability, the risks of rock bursts were verified in the last 3 mines that did not participate in the training. Table 22 presents the specific information of the model evaluation.

According to Table 22, the results of the model evaluation were in agreement with the actual situations of rock bursts, which meant the hierarchic analysis method model was effective and reasonable in evaluating the risk of rock bursts in mines, and the results have guiding significance in practice.

\section{Conclusions}

(1) The probability of rock bursts is random to a certain extent. By building a model of hierarchic analysis method, the reasons for rock bursts in mines were made quantitative, and the influence was considered by various factors and the relationship between them. The model was simple, flexible, and easy to operate.

(2) The risk degree of rock bursts evaluated through the hierarchic analysis method was in accordance with the actual degrees of risk. This indicated the assessment results of the model have some significance for mine production safety.

(3) The model of hierarchic analysis method obtained the influence degree and comprehensive evaluation indices of the factors that affect rock bursts. It can provide a theoretical basis for the prevention and control of rock bursts and can make the prevention and control more targeted and practical.

\section{Conflict of Interests}

The authors declare that there is no conflict of interests regarding the publication of this paper.

\section{Acknowledgments}

This paper is supported by "Natural Science Foundation of Jiangsu Province," China (Grant no. BK20130189), "Priority Academic Program Development of Jiangsu Higher Education Institutions," funded by the "Open Projects of State Key Laboratory of Coal Resources and Safe Mining," CUMT (SKLCRSM12X05, 14KF06), and "the Fundamental Research Funds for the Central Universities” (no. 2014XT01).

\section{References}

[1] M.-G. Qian and P.-W. Shi, Mining Pressure and Strata Control, China University of Mining and Technology Press, Xuzhou, China, 2003.

[2] Q.-X. Qi and L.-M. Dou, Rock Burst Theory and Technology, China University of Mining and Technology Press, Xuzhou, China, 2006.

[3] L. M. Dou, C. G. Zhao, S. G. Yang et al., Rock Burst Prevention in Coal Mining, China University of Mining and Technology Press, Xuzhou, China, 2006.

[4] Z.-L. Mu, "Study of the burst-energy principle of rock burst induced by roof stratum and its application," Journal of China
University of Mining and Technology, vol. 37, no. 6, pp. 149-150, 2008.

[5] Z.-L. Mu, L.-M. Dou, H. He, and J. Fan, "F-structure model of overlying strata for dynamic disaster prevention in coal mine," International Journal of Mining Science and Technology, vol. 23, no. 4, pp. 513-519, 2013.

[6] Z.-H. Li, L.-M. Dou, G.-X. Chen, H. Jiang, and T.-T. Du, “The risk of fault induced rockburst during mining," Journal of China University of Mining and Technology, vol. 39, no. 4, pp. 490-545, 2010.

[7] H. He, L.-M. Dou, S.-Y. Gong, P. Zhou, Z.-J. Xue, and H. Jiang, "Study of mining shock in high tectonic stress zones," Journal of Mining Science and Technology, vol. 40, no. 1, pp. 7-13, 2011.

[8] L.-M. Dou and X.-Q. He, "Technique of classification forecasting rock burst in coal mines," Journal of China University of Mining and Technology, vol. 36, no. 6, pp. 717-722, 2007.

[9] L.-M. Dou, C.-P. Lu, Z.-L. Mu, and M.-S. Gao, "Prevention and forecasting of rock burst hazards in coal mines," Mining Science and Technology, vol. 19, no. 5, pp. 585-591, 2009.

[10] Z.-H. Ge, F.-K. Xiao, L.-Q. Duan, and X. Meng, "Prediction of risk grade of impulsion pressure," Coal Technology, vol. 29, no. 11, pp. 100-102, 2010.

[11] E.-B. Yi, Z.-L. Mu, L.-M. Dou, X.-F. Xu, and L. Xie, "Study on fuzzy comprehensive evaluation on mine pressure bumping dangers," Coal Engineering, no. 6, pp. 70-72, 2011.

[12] X.-W. Li, L.-M. Dou, Z.-C. Wang, and Y.-Y. Zheng, "Fuzzy comprehensive evaluation method on rock burst relative risk zones dividing in working face," Mining Safety \& Environmental Protection, vol. 39, no. 1, pp. 79-82, 2012.

[13] D.-Z. Song, E.-Y. Wang, N. Li, M.-Y. Jin, and S.-P. Xue, "Rock burst prevention based on dissipative structure theory," International Journal of Mining Science and Technology, vol. 22, no. 2, pp. 159-163, 2012.

[14] A. C. Adoko, C. Gokceoglu, L. Wu, and Q. J. Zuo, "Knowledgebased and data-driven fuzzy modeling for rockburst prediction," International Journal of Rock Mechanics \& Mining Sciences, vol. 61, no. 4, pp. 86-95, 2013.

[15] L.-J. Dong, X.-B. Li, and K. Peng, "Prediction of rockburst classification using random forest," Transactions of Nonferrous Metals Society of China, vol. 23, no. 2, pp. 472-477, 2013.

[16] H. Li, Z. Li, R. He, and Y. Yan, "Rock burst risk evaluation based on particle swarm optimization and BP neural network," Journal of Mining and Safety Engineering, vol. 31, no. 2, pp. 203231, 2014.

[17] T. L. Saaty, The Analytic Hierarchy Process, McGraw-Hill, New York, NY, USA, 1980.

[18] Z.-H. Xie, MATLAB Statistical Analysis and Applications: 40 Case Studies, Beihang University Press, Beijing, China, 2010. 


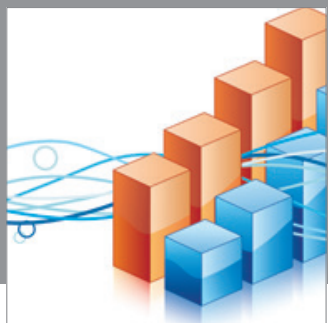

Advances in

Operations Research

mansans

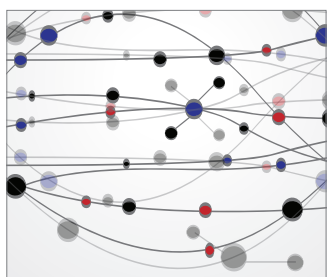

The Scientific World Journal
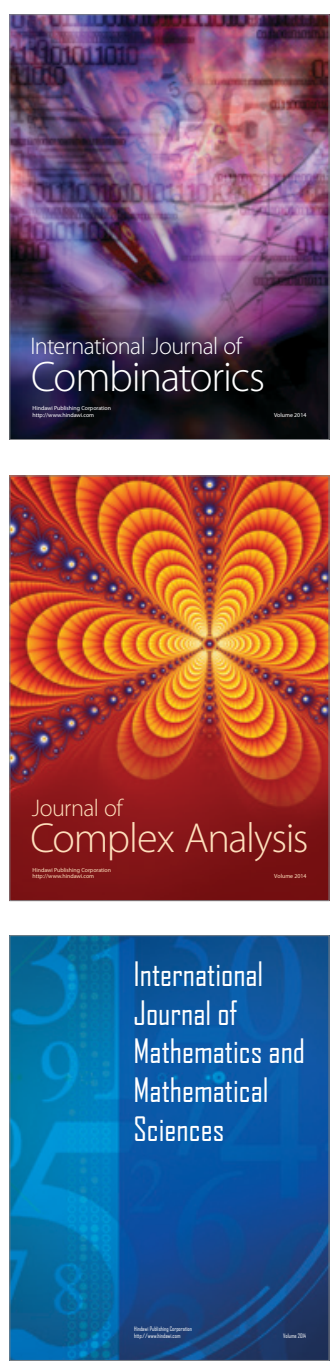
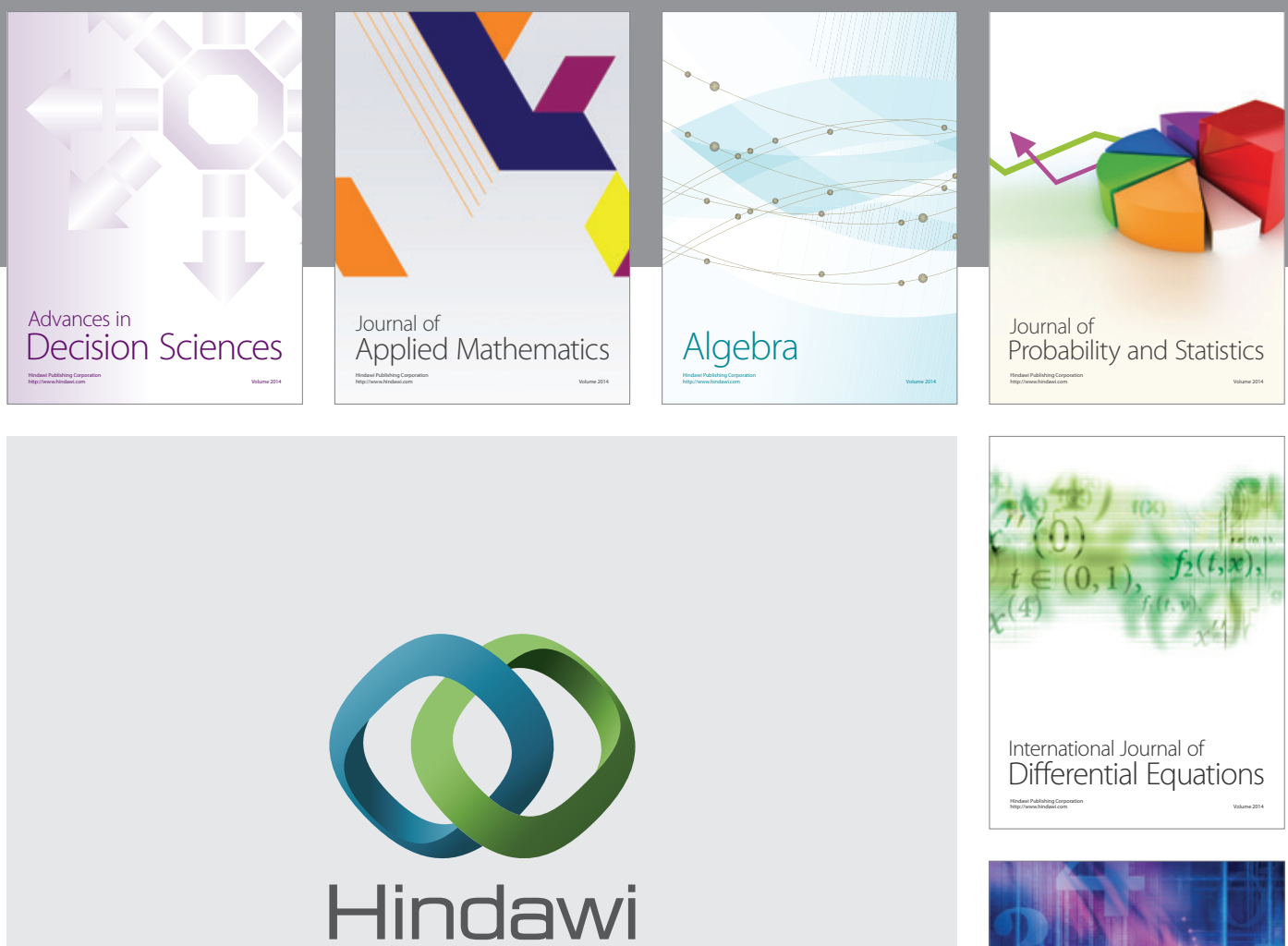

Submit your manuscripts at http://www.hindawi.com
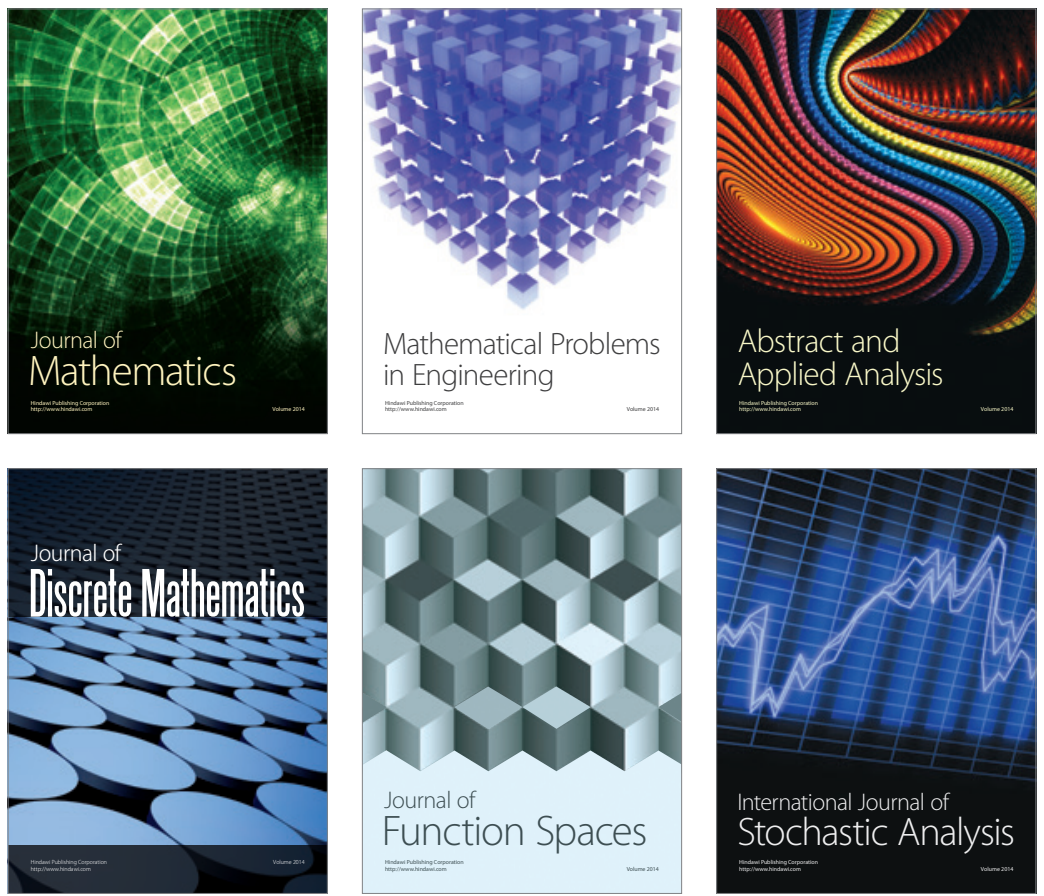

Journal of

Function Spaces

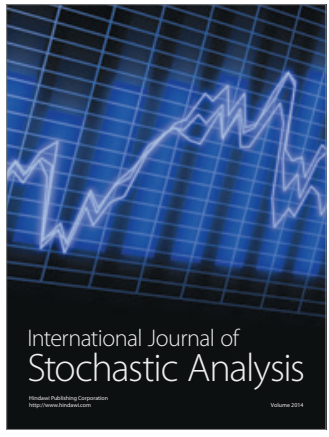

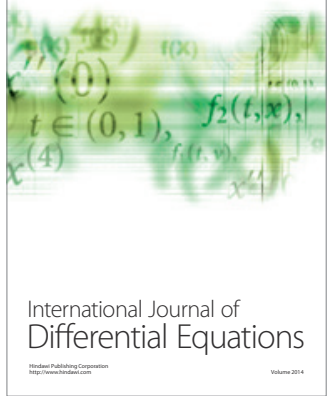
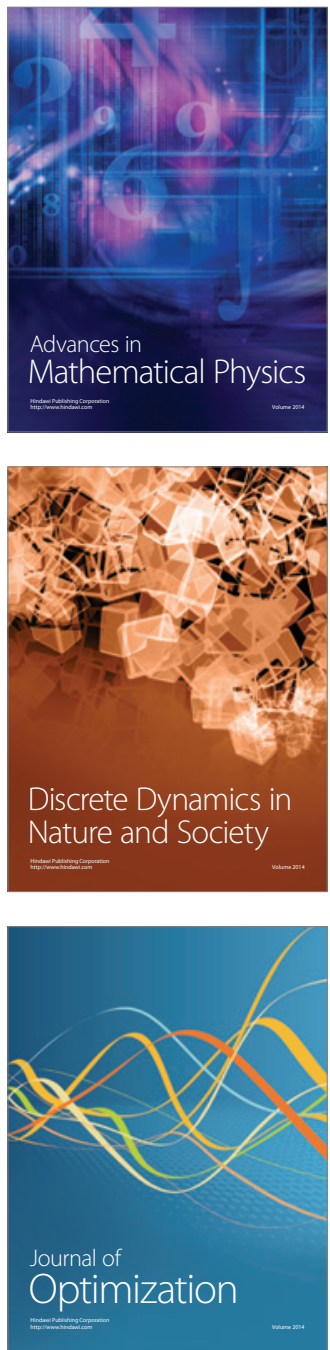